\title{
Prediction of cyclic residual stress relaxation by modeling approach
}

\author{
N. Ben Moussa ${ }^{1, a}$, N. Sidhom ${ }^{1, b}$, H. Sidhom ${ }^{1, c}$ and C. Braham ${ }^{2, d}$ \\ ${ }^{1}$ Mechanical, Material and Processes Laboratory (LR99ES05), ESSTT, 5, Avenue Taha Hussein \\ 1008, University of Tunis, Tunis, Tunisia. \\ ${ }^{2}$ Laboratoire de Procédés et Ingénierie en Mécanique et Matériaux (PIMM, UMR CNRS 8006), \\ Arts et Métiers- ParisTech, 151, Boulevard de l'Hôpital Paris 75013, France.
abmnaoufel2006@yahoo.fr , 'baziha.sidhom@gmail.com , chabib.sidhom@gmail.com, chedly.braham@paris.ensam.fr

Keywords: finite element method, cyclic residual stress relaxation, X-ray diffraction method, aluminum alloy.

\begin{abstract}
A new method for prediction of residual stress relaxation under cyclic loading has been developed and implemented in the finite element software Abaqus. The calculated profiles were validated by experimental measurements using X-ray diffraction method. This validated approach is afterward used to investigate the effect of loading path and initial residual stress characteristics on the kinetics of relaxation and the stabilized profile for both cyclic softening and cyclic hardening materials.
\end{abstract}

\section{Introduction}

The industrial components are frequently the seat of a distribution of residual stress led by manufacturing process [1-4] or by surface treatments [5]. Residual stress distributions, depending on process conditions and material nature, evolve in service according to the monotonous or cyclic loading. In the case of the cyclic loading, the residual stress relax more or less quickly according to the load path and amplitude to reach a stabilized state [6]. The stabilized residual stress allows explaining the mechanisms of initiating and growth of the fatigue cracks in several cases of mechanical component damage. In addition, the introduction of the residual stress stabilized state in multi-axial fatigue criteria improves their predictive aptitude $[5,6]$. That is why, it is imperative to follow the stability of an initial distribution of residual stress for reporting the premature failures and to assess improvements obtained by the superficial treatments [5].The experimental evaluation of residual stress profiles evolution during cyclic loading is expensive and leads to the destruction of many specimen. Consequently, experimental measurements by X-ray diffraction method are generally limited to the cyclic evolution of the surface residual stress or for a few numbers of relaxed profiles [7]. For these reasons, we propose, in this study, a numerical approach to predict the residual stress relaxation and stabilization. This approach is validated experimentally using X-ray diffraction method to evaluate residual stress induced in the aluminum alloy AA 5083-H111 machined by milling and treated by wire brush hammering. This approach allows following of residual stress redistribution during and after cyclic load for various parts geometries, loading paths and material cyclic behavior laws.

\section{Experimental procedure}

Wire brush hammering was applied to a notched fatigue-bending specimen using a stainless steel wire brush. The experimental conditions of the wire brush hammering are selected to have hammering without removal material where the brush speed, feed and the number of passes are equal to $630[\mathrm{rpm}], 50[\mathrm{~mm} / \mathrm{min}]$ and 7 passes respectively.

Four-point bending fatigue tests on hammered specimens are conducted using an MTS with different applied stress and stress ratio. 
The near surface residual stress distributions were evaluated before and after loading using the X-ray diffraction method (XRD) performed on the Proto XRD device, according to the conditions listed in Table 1. For in-depth measurements, material removal was performed by electropolishing method with an electrolyte composed by $8 \%$ (by volume) perchloric acid solution mixed in solution with $92 \%$ (by volume) of glacial acetic acid.

Table 1 X-ray diffraction parameters

\begin{tabular}{|c|c|}
\hline Radiation & $\operatorname{Cr} \operatorname{K} \alpha$ radiation $(\lambda=0.229[\mathrm{~nm}])$ \\
\hline Voltage & $30[\mathrm{kV}]$ \\
\hline Current & $5 \mathrm{~mA}$ \\
\hline X-ray diffraction planes & $\{311\}, 2 \theta=139.5$ \\
\hline Beam diameter & $2[\mathrm{~mm}]$ \\
\hline Angles $\varphi$ & $0^{\circ}$ and $90^{\circ}(2$ directions $)$ \\
\hline Oscillation $\psi$ & $\pm 3^{\circ}$ \\
\hline Tilt angles number & 17 \\
\hline
\end{tabular}

\section{Numerical procedure}

To asses residual stress relaxation by cyclic four-point bending loading, a numerical procedure based on a 2D finite element model is established using Abaqus-Standard software (Fig. 1). Since the thickness of the bending specimen is large $(\mathrm{e}=10 \mathrm{~mm})$ compared to the deformed zone, the assumption of plane strain was selected.

Due to symmetry only the half of the notched bending specimen is analyzed, and it is meshed using 4020 continuum-brick elements CPE4 (4-node bilinear plane strain quadrilateral) available in Abaqus element library. The mesh is highly refined near the notch until a length of $15 \mu \mathrm{m}$ (Fig. 2).

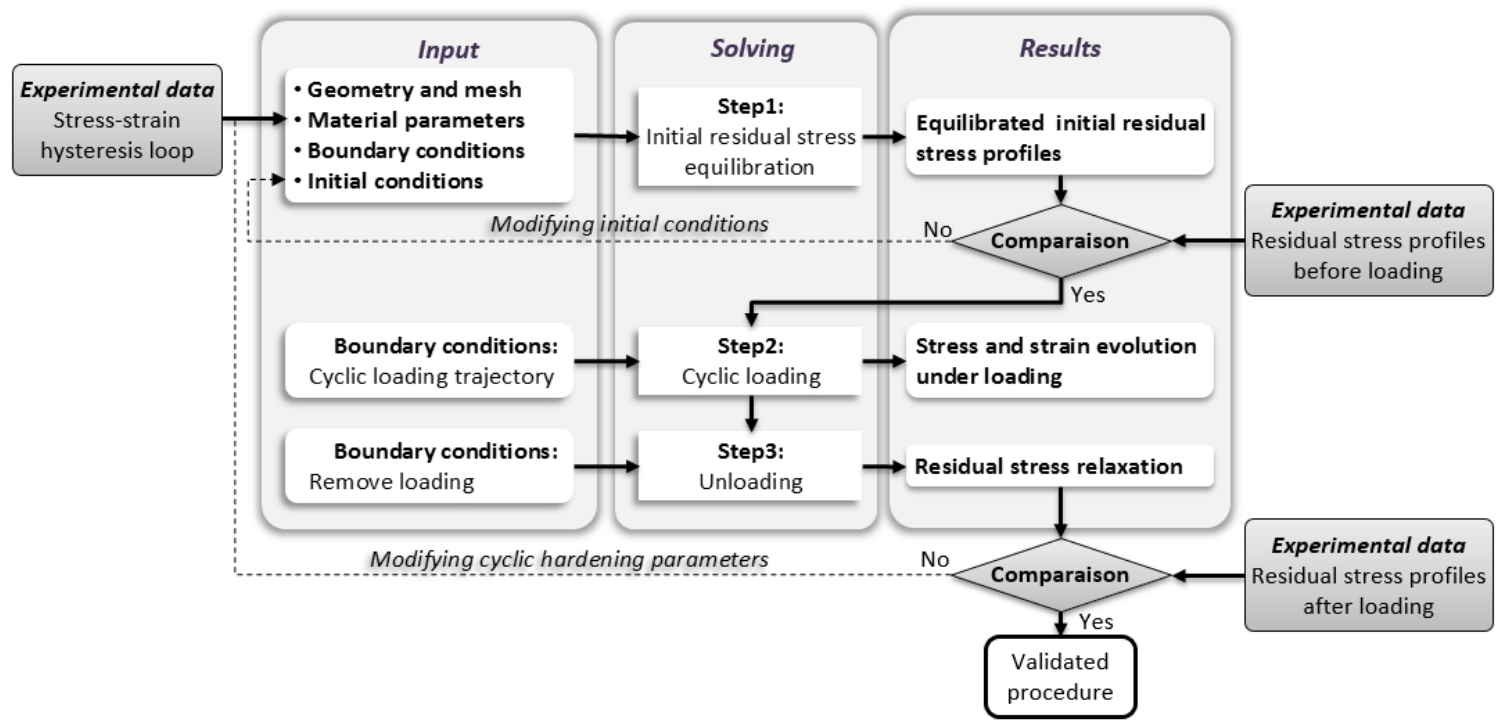

Fig. 1 Numerical procedure for residual stress relaxation prediction 


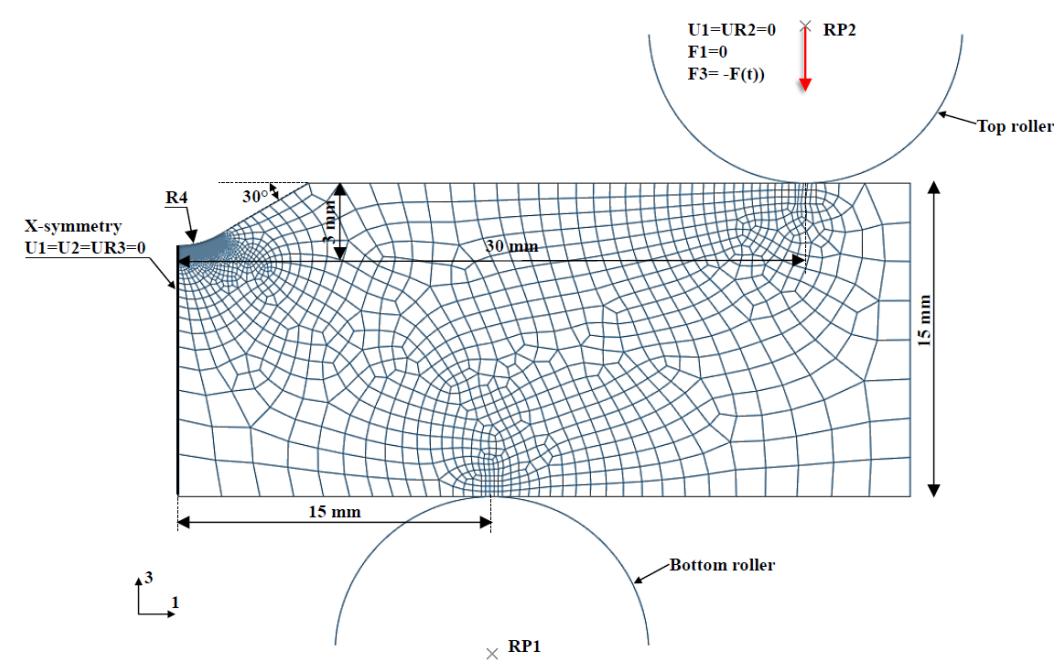

Fig. 2 Finite element model for residual stress relaxation prediction

\section{Loading and boundary conditions}

Appropriate four-point bending boundary conditions are imposed on the half of the notched bending specimen (Fig. 2). To account for the whole of specimen in calculation, an X-symmetry condition (U1=UR2 $=\mathrm{UR} 3=0)$ is applied to the cross section of bending specimen. The bottom roller is considered as an analytical rigid part controlled by a reference point RP1 where Dirichlet boundary conditions $(\mathrm{U} 1=\mathrm{U} 2=\mathrm{U} 3=\mathrm{UR} 1=\mathrm{UR} 2=\mathrm{UR} 3=0)$ are applied. The top roller is considered as an analytical rigid part controlled by a reference point RP2 where Dirichlet boundary conditions $(\mathrm{U} 1=\mathrm{UR} 2=0)$ and force $(\mathrm{F} 1=0, \mathrm{~F} 3=-\mathrm{F}(\mathrm{t}))$ are applied to describe cyclic bending loading. The timeevolution of bending force amplitude is defined as a Fourier series:

$$
F(t)=F_{m}\left[\mathrm{~A}_{0}+\sum_{n=1}^{N}\left(\mathrm{~A}_{\mathrm{n}} \cos \mathrm{n} \omega\left(t-t_{0}\right)+\mathrm{B}_{\mathrm{n}} \sin \mathrm{n} \omega\left(t-t_{0}\right)\right)\right]
$$

where $F_{m}$ is the mean bending force, $\mathrm{A}_{0}$ is the initial amplitude, $\mathrm{A}_{\mathrm{n}}$ and $\mathrm{B}_{\mathrm{n}}$ are constants defining the amplitude shape, $\omega=2 \pi f$ is the loading pulsation where $\mathrm{f}$ is the frequency and $\mathrm{t}$ is the loading time.

The behavior of the aluminum alloy AA5083-H111 under cyclic loading is described in this work by the isotropic and nonlinear kinematic hardening model proposed by Chaboche [8]. In this model, the yield criterion of von Mises, the plastic flow rule and the hardening variables are given by equations $2-5$.

- Yield criterion

$$
f=J_{2}(\sigma-X)-R-k=|\sigma-X|-R-k \leq 0
$$

- Flow rule

$$
\dot{\varepsilon}^{p}=\dot{p} \frac{\partial f}{\partial \sigma}=\left(\frac{2}{3} \dot{\varepsilon}^{p}: \dot{\varepsilon}^{p}\right)^{1 / 2} \frac{(\sigma-X)}{|\sigma-X|}
$$

- Isotropic hardening

$$
\left\{\begin{array}{c}
R=b(Q-R) \dot{p} \\
R=Q\left(1-e^{-b p}\right)
\end{array}\right.
$$

- kinematic hardening $\left\{\begin{array}{c}X=\frac{2}{3} C \dot{\varepsilon}_{p}-\gamma X \dot{p} \\ X_{M}=\frac{\Delta \sigma}{2}-k=\frac{C}{\gamma} \operatorname{th}\left(\gamma \frac{\Delta \varepsilon_{p}}{2}\right)\end{array}\right.$

where $\mathrm{X}$ is the back stress indicating the center of the yield stress surface, $\mathrm{R}$ is the drag stress describing the change in the size of the yield surface, $\mathrm{k}$ is the initial size of the yield surface, $\dot{p}$ is the cumulated plastic strain rate. The material coefficients $\mathrm{k}, \mathrm{Q}, \mathrm{b}, \mathrm{C}$ and $\gamma$, reported in Table 2, are 
identified for the AA 5083-H111 alloy, from experimental stress -strain hysteresis loops corresponding to different imposed strain range in accordance with Chaboche procedure [8].

Table 2. Cyclic behavior law coefficients of AA 5083-H111

\begin{tabular}{|l|l|l|l|l|l|c|}
\hline $\mathrm{E}[\mathrm{GPa}]$ & $v$ & $\mathrm{~K}[\mathrm{MPa}]$ & $\mathrm{Q}[\mathrm{MPa}]$ & $\mathrm{b}$ & $\mathrm{C}[\mathrm{MPa}]$ & $\gamma$ \\
\hline 70 & 0.33 & 100 & 103 & 6.44 & 30000 & 350 \\
\hline
\end{tabular}

The experimental profiles of residual stress induced by wire brush hammering are accounted by the FE models as an initial condition using a subroutine SIGINI written in FORTRAN language. In this subroutine the stresses in both directions have been introduced a function of coordinates. These stresses were equilibrated in a first STEP of calculation and their concordance with experimental measurements was verified (Fig. 3 a,b).

\section{Results and discussion}

Experimental and simulation results (Fig. 3 a,b) show that wire brush hammering operations induce in affected layers a biaxial distribution of compressive residual stresses. These residual stresses are generated by wire brush bombarding of the surface leading to plastic deformation of thin surface layers which changes the dislocation density. The sub-surface layers stressed elastically try to return in their initial state after treatment, but this process is prevented by the permanent plastic deformed surface layers. Then a compressive residual stress field is generated on the surface and in the near surface layers, while tensile residual stresses are developed in the underneath layers. Moreover, the higher levels of the stresses are achieved at surface for the two measurements directions. They reached $-180 \mathrm{MPa}$ (equivalent to 1.28 bulk material yield stress) at the longitudinal direction and $-125 \mathrm{MPa}$ (equivalent to 0.9 bulk material yield stress) at the transversal direction. The wire brush compressed layers reached values ranging from 50 to $80 \mu \mathrm{m}$.

After several simulations it has been established the residual stress do not evolve significantly after 50 cycles. Fig. 3 (c,d) illustrates the predicted and measured residual stress profiles for the same cyclic loading conditions. The simulation results show a satisfactory agreement between calculated and measured residual stresses proving the satisfactory capability of the suggested numerical procedure.

The XRD measurements of the post fatigue residual stress were performed at the notch root zone of fatigue tested specimen at the stress level near to fatigue limit. Experimental and numerical results indicated that the applied bending fatigue stress modifies the wire brush hammering induced residual stress magnitude and depth (Fig. 3). These modifications are the consequence of plastic strain creation and redistribution during cyclic load (Fig. 4). In fact, the stress distribution resulting from superposition of applied bending stress and initial residual stress fields lead to exceeding the local yield stress limit and the creation of a plastic strain distribution. This distribution evolves during cyclic load depending on applied bending stress and stress ratio. Fig. 5 shows that residual stress in both directions evolves rapidly during first cycles and stabilizes at the 50th cycle. This result can be explained by cyclic softening of the material which occurs mostly during the first cycles. A simulation was conducted with a coefficient Q equal to 103 [MPa] to describe a cyclic hardening behavior of material (Fig.4b). The evolution of stress and strain, during cyclic load, show that the residual stress relaxation is more important for softening behavior material. This result can be explained by a higher plastic strain level created by cyclic bending loading for cyclic softening behavior where the yield stress decreases during cycling. Fig. 6 shows that the residual stress relaxation depends on the cyclic load trajectory. In fact, a higher compressive residual stresses is obtained where applied load or stress ratio increase. This result can be explained by supplementary residual stress creation by cyclic bending loading on notched specimen. 


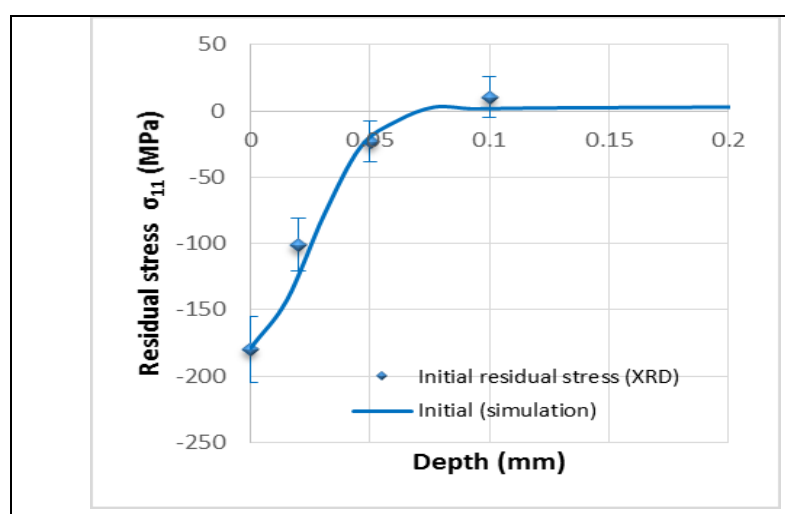

(a)

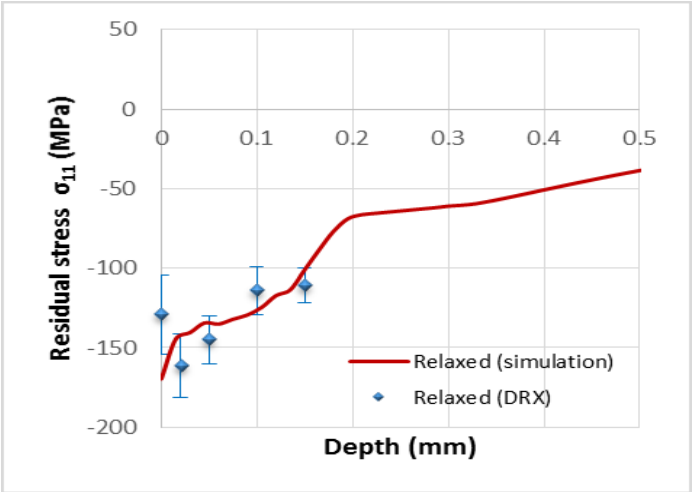

(c)

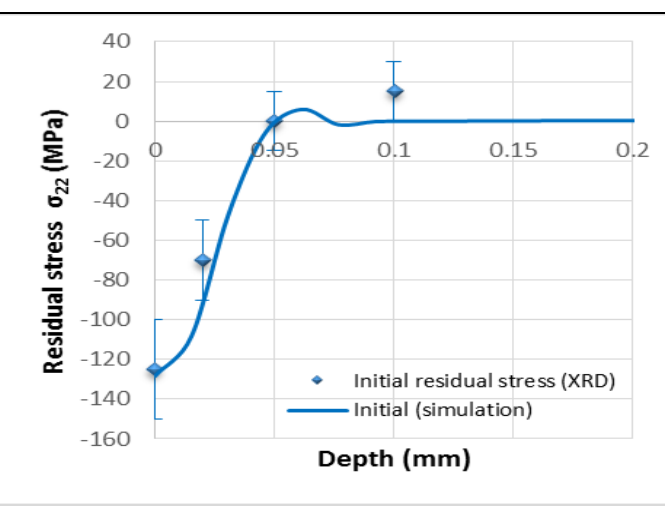

(b)

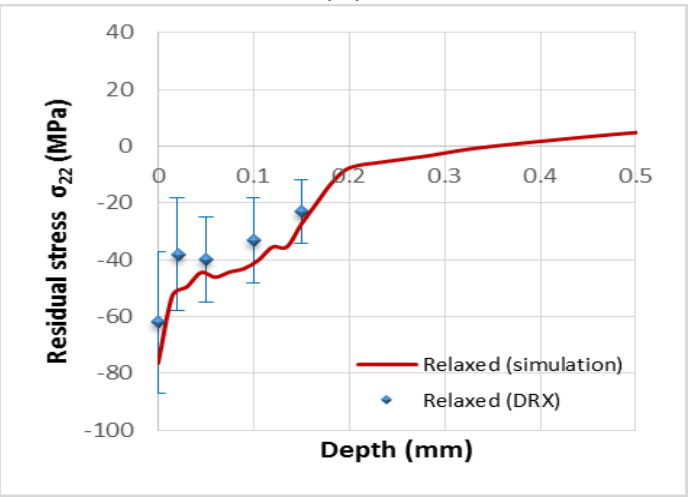

(d)

Fig. 3 Measured and predicted residual stress induced by wire brush hammering, a and b: initial state, $\mathrm{c}$ and $\mathrm{d}$ : after loading at $\mathrm{Fm}=5.7[\mathrm{kN}]$ and $\mathrm{R}=0.1$.

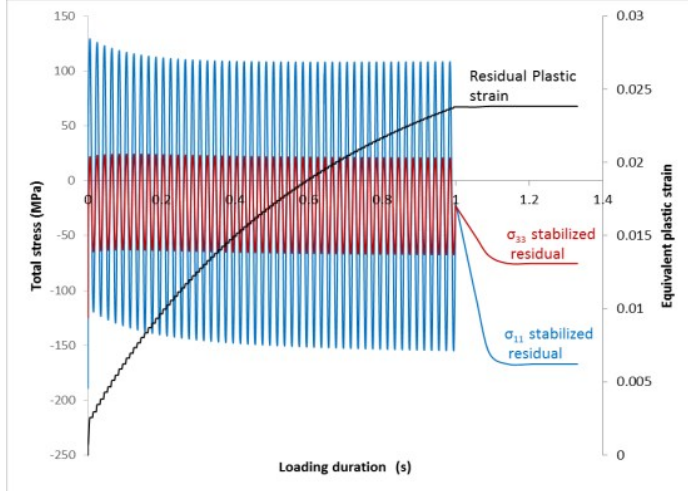

(a)

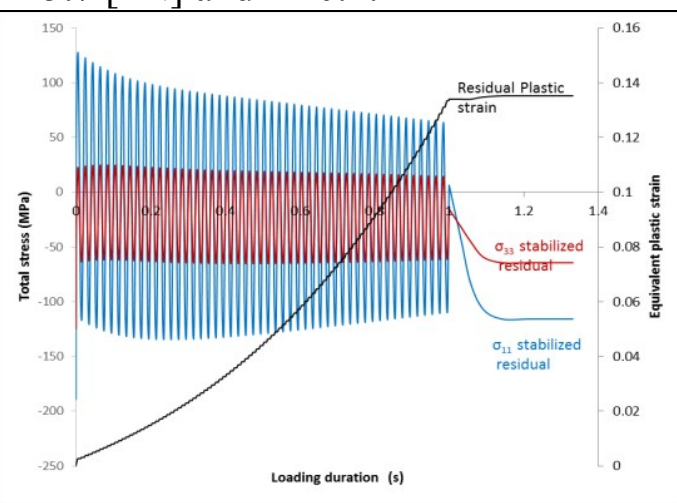

(b)

Fig. 4 Cyclic stress and strain evolutions of wire brush hammering residual stress at $\mathrm{Fm}=6[\mathrm{kN}]$ and stress ratio $\mathrm{R}=0.1$, a: cyclic hardening behavior $(\mathrm{Q}=103[\mathrm{MPa}])$, $\mathrm{b}$ : softening cyclic behavior $(\mathrm{Q}=-103[\mathrm{MPa}])$
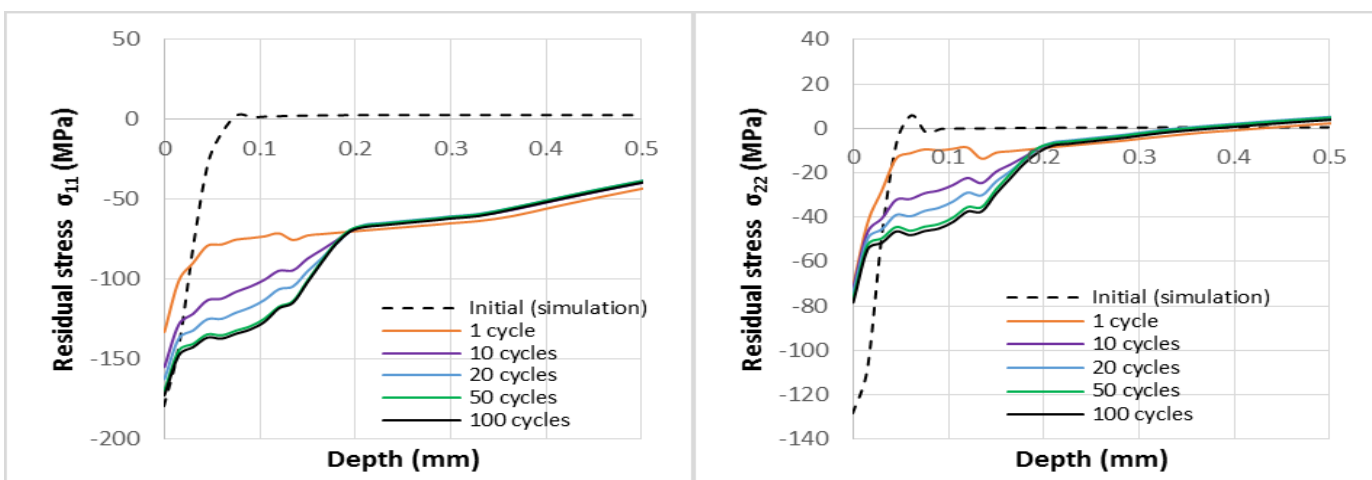

Fig. 5 Cyclic evolution of residual stress under cyclic bending load at $\mathrm{Fm}=5.7[\mathrm{kN}]$ and $\mathrm{R}=0.1$. 


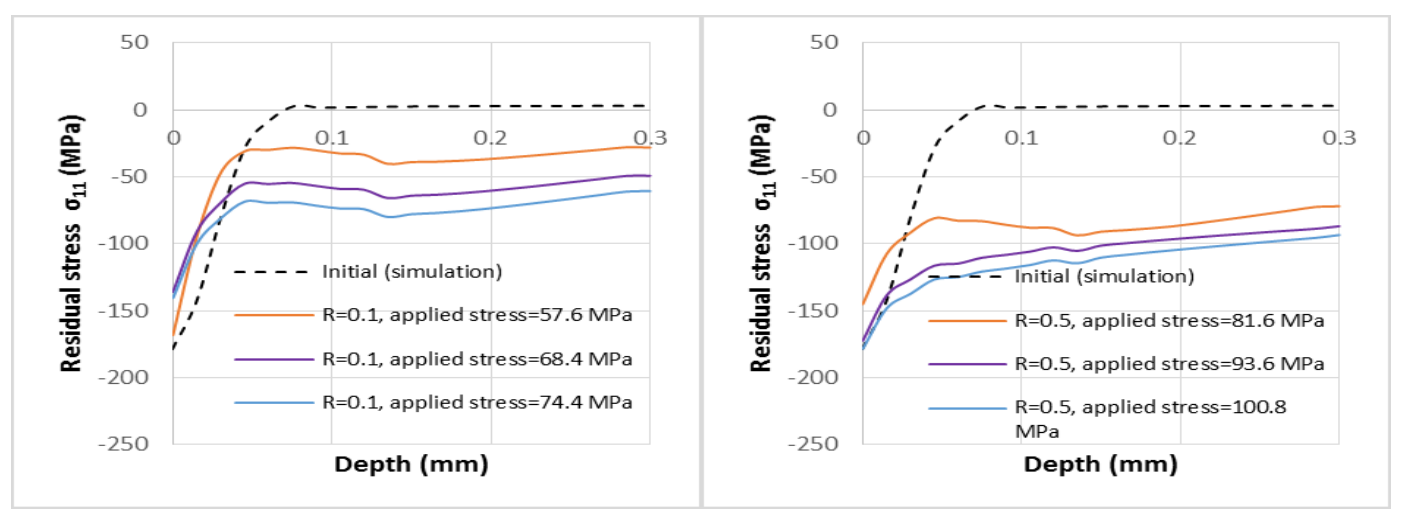

Fig. 6 Effect of bending amplitude and stress ratio on residual stress relaxation (after 50 cycles).

\section{Conclusion}

The numerical approach proposed in this work allows predicting the relaxation and stabilization of residual stress induced by wire brush hammering. This approach is validated experimentally using X-ray diffraction method to evaluate residual stress induced in the aluminum alloy AA 5083H111 machined by milling and treated by wire brush hammering. This approach allows to follow the redistribution of residual stress during and after cyclic load for various loading paths and material cyclic behavior laws giving explication of residual stress relaxation by plastic strain redistribution during cyclic loading.

\section{References}

[1] Ben Moussa N., Sidhom H., Braham C., Numerical and experimental analysis of residual stress and plastic strain distributions in machined stainless steel, International Journal of Mechanical Sciences, 64 (2012) 82-93.

[2] B. C., Ben Rhouma A., Lédion J., Sidhom H., Effect of machining conditions on residual stress corrosion cracking of 316L SS, in: ICRS-7 (Ed.) 7th International Conference on Residual Stresses, Xi'an, 2005, pp. 305-310.

[3] F. Ghanem, C. Braham, H. Sidhom, Influence of steel type on electrical discharge machined surface integrity, Journal of Materials Processing Technology, 142 (2003) 163-173.

[4] Z. Al-Adel, N. Ben Moussa, H. Yahyaoui, H. Sidhom, Surface Integrity after Orthogonal Cutting of Aeronautical Aluminum Alloy 7075-T651, Design and modeling of mechanical systems, (2013) 485-492.

[5] N. Sidhom, A. Laamouri, R. Fathallah, C. Braham, H.P. Lieurade, Fatigue strength improvement of $5083 \mathrm{H} 11$ Al-alloy T-welded joints by shot peening: experimental characterization and predictive approach, International Journal of Fatigue, 27 (2005) 729-745.

[6] A. Laamouri, H. Sidhom, C. Braham, Evaluation of residual stress relaxation and its effect on fatigue strength of AISI 316L stainless steel ground surfaces: Experimental and numerical approaches, International Journal of Fatigue, 48 (2013) 109-121.

[7] J.T. Maximov, G.V. Duncheva, I.N. Mitev, Modelling of residual stress relaxation around cold expanded holes in carbon steel, Journal of Constructional Steel Research, 65 (2009) 909-917.

[8] J. Lemaitre, J. Chaboche, Mécanique des matériaux solides, Dunod, Paris, (2001). 